This is the peer reviewed version of the following article: Angew. Chem. Int. Ed. 2017, 56, 4936-4940, which has been published in final form at https://onlinelibrary.wiley.com/doi/abs/10.1002/anie.201612149. This article may be used for non-commercial purposes in accordance with Wiley Terms and Conditions for Use of Self-Archived Versions.

\title{
Catalytic Asymmetric Intramolecular [4+2] Cycloaddition of in situ Generated ortho-Quinone Methides
}

Youwei Xie, and Benjamin List*

\begin{abstract}
Here we describe the first catalytic asymmetric intramolecular [4+2] cycloaddition of in situ generated ortho-quinone methides. Catalyzed by a confined chiral imidodiphosphoric acid, various salicylaldehydes react with dienyl alcohols to give transient ortho-quinone methide intermediates, which undergo an intramolecular [4+2] cycloaddition to provide highly functionalized furanochromanes and pyranochromanes in excellent diastereoselectivity and enantioselectivity.
\end{abstract}

o-Quinone methides (o-QMs) have been well-studied and applied in a variety of transformations during the last few decades. ${ }^{[1]}$ They are also the key intermediates in a number of biomimetic natural product syntheses, typically engaging in [4+2] hetero-Diels-Alder reactions. ${ }^{[1 a, 2]}$ Several approaches have been developed towards in situ generation of these highly reactive intermediates, ${ }^{[3-10]}$ and their application in catalytic asymmetric transformations. ${ }^{[10]}$ However, there are only few reports on catalytic asymmetric [4+2] cycloadditions of o-QMs, ${ }^{[1]}$ and an intramolecular variant is, to the best of our knowledge, completely unknown. The development of such a transformation occurred to be desirable to us as it would allow direct access to various tricyclic frameworks with a chromane moiety, a structural motif frequently seen in natural products (Figure 1). Here, we show that by utilizing a confined Brønsted acid catalyst, ${ }^{[2]}$ this transformation can indeed be accomplished highly stereoselectively.

The challenges of applying o-QMs in asymmetric [4+2] cycloadditions are not only associated with their transient nature, but also with their weak and ill-defined interactions with enantiopure catalysts. Existing methods rely on either simultaneously activating both the $\mathrm{o}-\mathrm{QM}$ and its reaction

$\left[{ }^{*}\right] \quad$ Dr. Y. Xie, Prof. Dr. B. List

Max-Planck-Institut für Kohlenforschung

Kaiser-Wilhelm-Platz 1, 45470 Mülheim an der Ruhr (Germany) E-mail: list@kofo.mpg.de

Generous support from the Max-Planck-Society and the European Research Council (Advanced grant CHAOS) is gratefully acknowledged. Y. X. thanks the Alexander von Humboldt Foundation for a postdoctoral fellowship. We also thank out technicians, the members of our GC, HPLC, and crystallography departments for their excellent support.

Supporting information for this article is available online at https://onlinelibrary.wiley.com/doi/abs/10.1002/anie.201612149. partner, ${ }^{[11]}$ or on the exclusive activation of 0 -QMs towards cycloadditions with styrenes. ${ }^{[11 \mathrm{~b}]}$

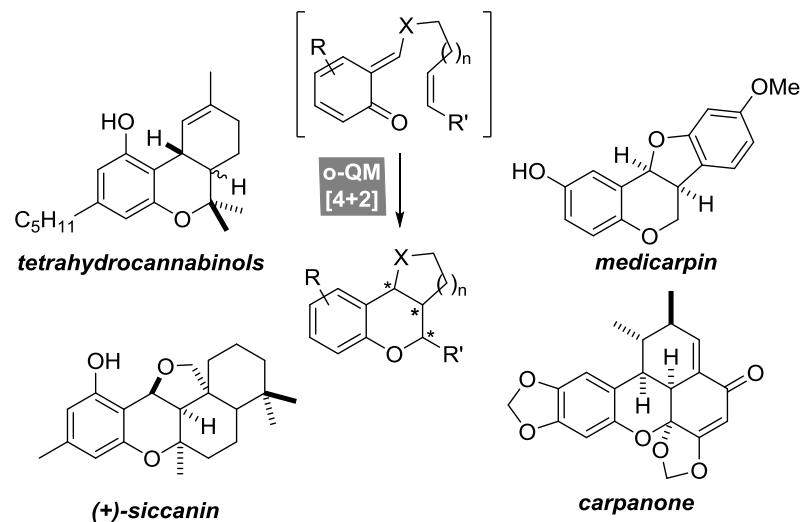

Figure 1. Tricyclic chromane moieties that appear in various natural products.

Non-asymmetric intramolecular [4+2] cycloadditions have previously been developed and suggested to proceed via protonated $0-Q M s .{ }^{[13-16]}$ We hypothesized that the confined chiral pocket of the imidodiphosphoric acid catalysts ${ }^{[12]}$ could provide sufficient activation and enantiodifferentiation for this reaction. Indeed, upon treating salicylaldehyde (1a) with dienyl alcohol $\mathbf{2 a}$ in the presence of TRIP (4a), product $\mathbf{3 a}$ was isolated in poor yield and moderate selectivity (Scheme 1).

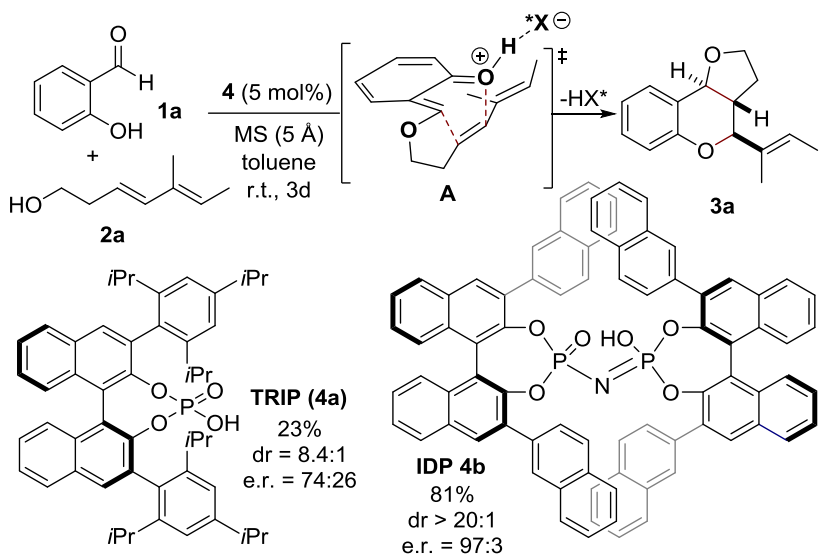

Scheme 1. Catalytic asymmetric intramolecular [4 +2] cycloaddition of in situ formed o-QMs catalyzed by TRIP (4a) and confined Brønsted acid IDP (4b). 
However, significantly improved yield and selectivity could be achieved by using imidodiphosphoric acid catalyst $\mathbf{4 b}$, which catalyzed the reaction efficiently to give $\mathbf{3 a}$ as the only isolable product in $81 \%$ NMR yield with an excellent enantiomeric ratio of 97:3. The enantiomeric ratio could be further increased to $99: 1$ by using cyclohexane as a solvent (see Supporting Information for more details of catalyst and reaction condition optimization). The application of a dienyl alcohol such as $\mathbf{2 a}$ was crucial for high reactivity and selectivity, and switching to other homoallylic alcohols with isolated alkene moieties led to significantly reduced reactivity and selectivity (Table S6).

Table 1. [4 + 2] Cycloaddition of different salicylaldehyde derivatives. ${ }^{[a]}$

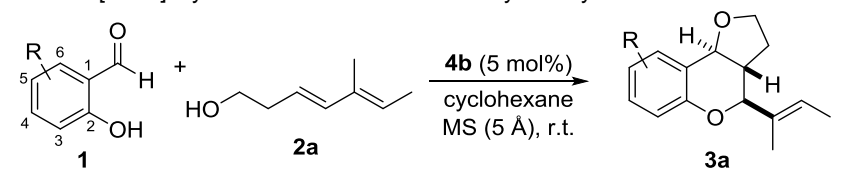

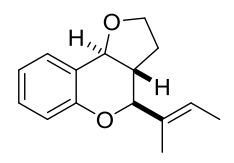

3a

2 d, $84 \%, 99: 1$ e.r<smiles>C/C=C(\C)[C@H]1Oc2ccc(C)cc2[C@H]2OCC[C@@H]12</smiles>

3d

3 d, $84 \%, 98.5: 1.5$ e.r.<smiles>C/C=C(\C)[C@H]1Oc2ccc(C(C)(C)C)cc2[C@H]2OCC[C@H]12</smiles>

$3 \mathrm{~g}$

3 d, $91 \%, 99: 1$ e.r.

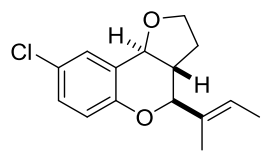

$3 \mathbf{i}$

24 h, $81 \%, 98.5: 1.5$ e.r.<smiles>C/C=C(/C)[C@H]1Oc2c(Br)cc(Cl)cc2[C@H]2OCC[C@@H]12</smiles>

3I<smiles>C/C=C(/C)C1Oc2ccc(OC)cc2[C@H]2OCC[C@H]12</smiles>

3b

16 h, $83 \%$, $98: 2$ e.r.

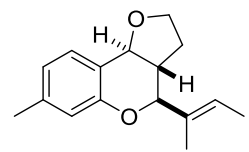

2 d, $80 \%, 98: 2$ e.r.<smiles>C/C=C(\C)[C@H]1Oc2ccc(F)cc2[C@H]2OCC[C@@H]12</smiles>

3h

2 d, $80 \%, 99: 1$ e.r.<smiles>C/C=C(\C)[C@H]1Oc2ccc(Br)cc2[C@H]2OCC[C@@H]12</smiles>

3j

4 d, $80 \%, 99: 1$ e.r.

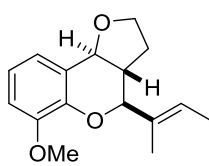

$3 \mathrm{~m}$

2 d, $81 \%, 92: 8$ e.r

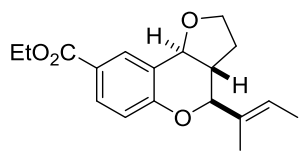

$3 c$

1 d, $86 \%, 98.5: 1.5$ e.r.

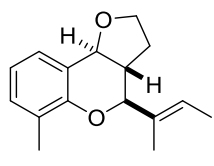

6 d, $84 \%, 96: 4$ e.r.
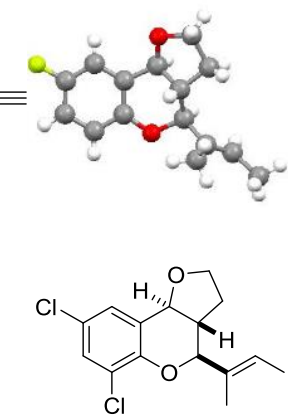

$3 k$

3 d, $82 \%, 98: 2$ e.r.

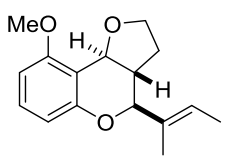

$3 n$

$3 \mathrm{~d}$, trace [a] Reactions were performed using catalyst $4 \mathrm{~b}$ (5 mol\%), 1.05 equiv. of aldehyde 1, 1.0 equiv. of diene $2 \mathbf{a}$ and $5 \AA$ molecular sieves $(0.3 \mathrm{~g} / \mathrm{mmol})$ in cyclohexane $(0.1 \mathrm{M})$, at r.t. for the indicated period of time, isolated yields, d.r. $>20: 1$ for all substrates shown.

With the optimized reaction condition in hand, we next explored the scope of this reaction (Table 1). A variety of commercially available salicylaldehyde derivatives were tested using $5 \mathrm{~mol} \%$ of catalyst $\mathbf{4 b}$. Electron-neutral (1a, 1d), electron-rich (1b), electron-poor (1c) and sterically bulky substituent $(\mathbf{1 g})$ were all tolerated at the 5-position of the aromatic ring, and the corresponding products were obtained in good yields with excellent diastereo- and enantioselectivity. Substituents at the 3- and 4-positions (1e, 1f, $\mathbf{1 m})$ are well tolerated as well. Halogenated $(\mathbf{3} \mathbf{h}-\mathbf{3} \mathbf{j})$ and dihalogenated $(\mathbf{3} \mathbf{k}, \mathbf{3} \mathbf{l})$ products could also be obtained in good yields and excellent selectivity suggesting further functionalizations of the aromatic ring to be possible. Only a substrate with substitution at the 6-position did not provide the corresponding product in detectable amount (3n). The absolute configuration of product $3 \mathbf{h}$ was unambiguously assigned by single-crystal X-ray analysis while that of the others was assigned by analogy (Table 1 and Figure S1). ${ }^{[19]}$ temperature (see the Supporting Information).

We also explored several dienyl alcohols with different substitution patterns (Table 2). Substrates with less substitution (2b), longer alkyl chain substituents (2c, 2d), or an aromatic substituent $(\mathbf{2 e})$ were all well tolerated. When the distant alkene was part of a ring (2f), tetracyclic product $\mathbf{5 f}$ could be obtained in good yield and excellent selectivity. The distant alkene could also be replaced by a phenyl group (2g), and the corresponding product $\mathbf{5 g}$ was obtained in excellent selectivity. Furthermore, this method was equally efficient in the synthesis of a pyranochromane, and product $5 \mathrm{~h}$ was isolated as the only product in good yield and excellent selectivity when the homolog of $\mathbf{2 a}, \mathbf{2} \mathbf{h}$ was used. A dienyl alcohol with a terminal alkene was

Table 2. [4 + 2] Cycloaddition of different dienyl alcohol derivatives. ${ }^{[a]}$

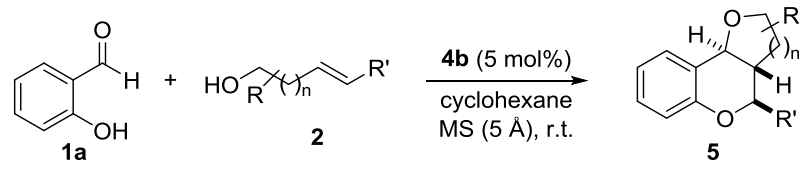

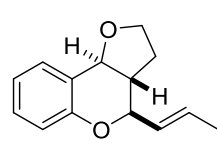

5b

2 d, $78 \%, 98: 2$ e.r.<smiles>C/C=C(\c1ccccc1)C1Oc2ccccc2[C@H]2OCC[C@@H]12</smiles>
$5 \mathbf{e}$

4 d, $87 \%, 98: 2$ e.r.<smiles>C/C=C(\C)[C@H]1Oc2ccccc2[C@H]2OCCC[C@@H]12</smiles>

5 h

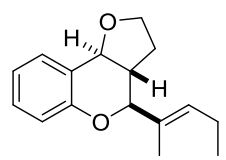

$5 c$ 3 d, $81 \%, 98: 2$ e.r.<smiles>Br[C@H]1Oc2ccccc2[C@H]2OCC[C@H]21</smiles>

2 d, $81 \%, 99: 1$ e.r.<smiles>C/C=C/C1Oc2ccccc2[C@H]2OCC(C)[C@H]12</smiles>

$5^{[\mathrm{b}]}$

d, $83 \%,>99: 1$ e.r.

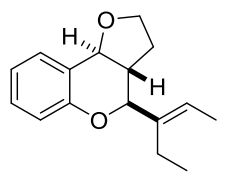

$5 d$ 3 d, $82 \%, 97.5: 2.5$ e.r.

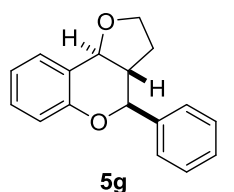

5 d, $83 \%, 98.5: 1.5$ e.r.

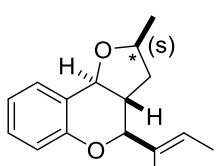

$5 j^{[\mathrm{b}]}$
$3 d, 75 \%, 98: 2$ e.

[a] Reactions were performed using catalyst $4 \mathbf{b}$ ( $5 \mathrm{~mol} \%), 1.05$ equivalent of 1a, 1.0 equivalent of 2 and $5 \AA$ molecular sieves $(0.3 \mathrm{~g} / \mathrm{mmol})$ in cyclohexane $(0.1 \mathrm{M})$, at room temperature for the indicated period of time, isolated yields, d.r. > 20:1 for all substrates shown. [b] The starting dienyl alcohol was enantiomerically pure and the absolute configuration is indicated in the product.

not suitable as substrate since the corresponding product was formed at extremely low reaction rate, even at elevated temperature (see the Supporting Information).

Structurally more complex furanochromanes could be obtained when enantiomerically enriched chiral dienyl alcohols were used. A "match" and "mismatch" effect was observed for these 
substrates depending on the absolute configuration of the chiral dienyl alcohol starting material. In the matched case, the corresponding product was formed in excellent diastereoselectivity $(\mathbf{5 i}, \mathbf{5} \mathbf{j}$ in table 2 ), while in the mismatched case, the corresponding product was obtained with moderate diastereoselectivity (5i', 5j' in table S7). In both cases, no erosion of enantiopurity was observed, and the products were observed with the same level of enantiopurity as their starting alcohols. When an achiral catalyst was used, a complex mixture of four to eight diastereomers was obtained, again supporting the excellent control enabled by confined acid catalyst $\mathbf{4 b}$ in activating o-QMs for stereoselective transformations (see table $\mathrm{S} 7$ in the Supporting Information).

Encouraged by these results we next explored the possibility of developing a diastereoselective and enantioselective synthesis of furanochromanes from racemic chiral dienyl alchohols via kinetic resolution $(\mathrm{KR})$. Indeed, as shown in Scheme 2, chiral alcohols (rac)-2i or (rac)-2j were exposed to the reaction condition and after approximately 50\% conversion, products $\mathbf{5 i}$ or $\mathbf{5 j}$ were obtained in good yield with excellent enantioselectivity and moderate to good diastereoselectivity. The minor diastereomers 5i' and 5j' were also obtained with excellent enantioselectivity.
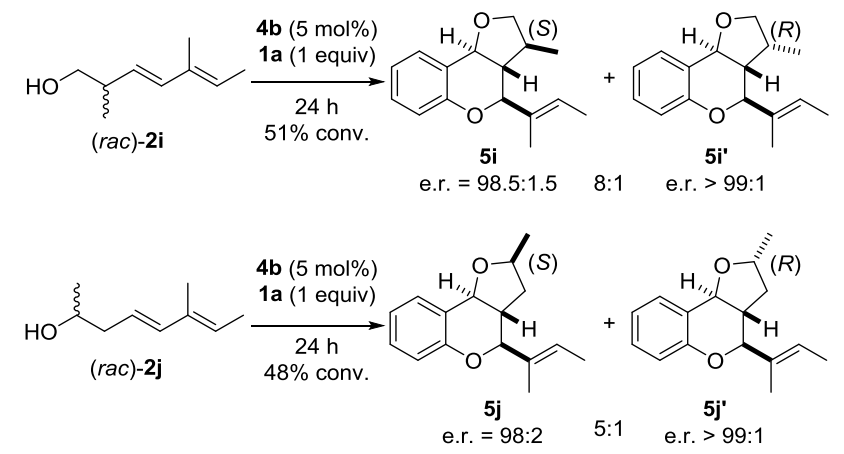

Scheme 2. Catalytic asymmetric intramolecular [4+2] cycloadditions of racemic dienyl alcohols via kinetic resolution $(\mathrm{KR})$.

A plausible mechanism is suggested in Scheme 3 for the reaction between salicylaldehyde (1a) and alcohol 2 catalyzed by confined acid $\mathbf{4 b}$. A dehydrative condensation of the two starting materials generates oxocarbenium ion I, a resonance structure of ortho-quinone methide II. Intermediate II within the chiral confinement pocket of catalyst $\mathbf{4 b}$ provides the desired activation towards the highly diastereoselective and enantioselective [4+2] cycloaddition to deliver product 5 (path a). An alternative stepwise pathway that involves a vinylogous Prins cyclization followed by intramolecular trapping of the cationic intermediate III by the phenol $\mathrm{OH}$ group can also be envisioned (path b). ${ }^{[20]}$

To gain more information on the reaction mechanism, we reacted aldehyde $\mathbf{1 a}$ with homoallylic alcohol cis-2g. While trans-2g gave the corresponding trans-product $\mathbf{5 g}$ in excellent diastereo- and enantioselectivity (Table 2), cis-2g gave a mixture of cis-products $\mathbf{5} \mathbf{g}^{\prime}$ and $\mathbf{5 g}$ " in moderate enantioselectivity (Scheme 4). Accordingly the stereochemical relationship of the C-C double bond was stereospecifically transferred into product in both cases (see scheme S1 in the Supporting Information). This result is consistent with the suggested concerted path $a$, even though stepwise path $b$ cannot be entirely ruled out at this point.

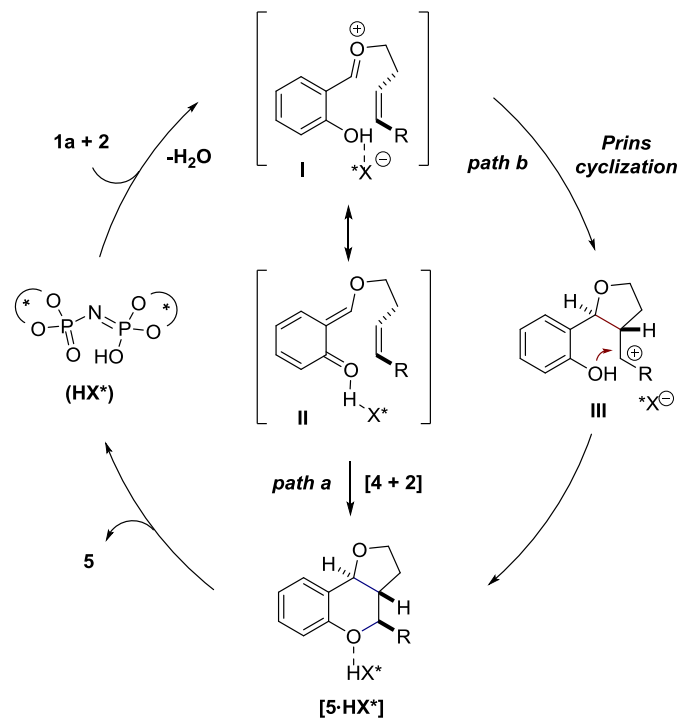

Scheme 3. Proposed mechanism of the catalytic asymmetric intramolecular [4+2] cycloaddition catalyzed by chiral imidodiphosphoric acid $\mathbf{4 b}$. $\left(\mathbf{H} \mathbf{X}^{\star}=\right.$ catalyst $\mathbf{4 b}$ )

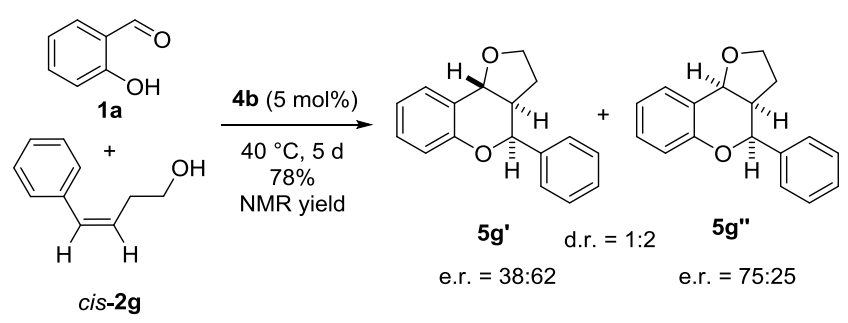

Scheme 4. Cycloaddition of aldehyde $\mathbf{1 a}$ with cis-2g

In summary, we have developed the first catalytic asymmetric intramolecular [4+2] cycloadditions of o-QMs. Our method allows fast access to a variety of highly functionalized furanochromane and pyranochromane derivatives. Diastereo- and enantioselective synthesis via kinetic resolution is possible when using racemic chiral dienyl alcohols. The high diastereo- and enantioselectivity observed in this reaction is a result of the activation of ortho-quinone methide intermediate in the confined chiral pocket of IDP catalyst $\mathbf{4 b}$. Even compared to the previously developed non-asymmetric variants, our method has a very broad substrate scope and the resulting products are functionalized for further elaboration. We envisage that this method can be applied in the asymmetric synthesis of a variety of useful natural products. Research along these lines is currently going on in our laboratory and will be reported in due course.

Keywords: hetero-Diels-Alder reaction $\cdot[4+2]$ cycloaddition $•$ ortho-quinone methide $\cdot$ organocatalysis $\bullet$ confined Brønsted acid

[1] Selected reviews of o-QMs: a) N. J. Willis, C. D. Bray, Chem. Eur. J. 2012, 18, 9160-9173; b) T. P. Pathak, M. S. Sigman, J. Org. Chem. 2011, 76, 9210-9215; c) S. B. Berreira, F. d. C. da Silva, A. C. Pinto, D. T. G. Gonzaga, V. F. Ferreira, J. Heterocycl. Chem. 2009, 46, 1080 1097; d) Quinone Methides (Eds.: E. Rokita), Wiley, New York, 2009, p 
412; e) C. M. Beaudry, J. P. Malerich, D. Trauner, Chem. Rev. 2005 105, 4757-4778; f) R. W. Van De Water, T. R. R. Pettus, Tetrahedron 2002, 58, 5367-5405; g) H. Amouri, J. Le Bras, Acc. Chem. Res. 2002 35, 501-510; h) Y. Chiang, A. J. Kresge, Y. Zhu, Pure Appl. Chem. 2000, 72, 2299-2308; i) P. Wan, B. Barker, L. Diao, M. Fischer, Y. Shi, C. Yang, Can. J. Chem. 1996, 74, 465-475.

[2] Selected recent examples of $o-Q M s$ in total synthesis: a) L. Xu, F. Liu, L.-W. Xu, Z. Gao, Y.-M. Zhao, Org. Lett. 2016, 18, 3698-3701; b) Y. Li B. Yu, R. Wang, Tetrahedron Lett. 2016, 57, 1856-1859; c) A. A. More, C. V. Ramana, Org. Lett. 2016, 18, 612-615; d) A. A. More, C. V Ramana, Org. Lett. 2016, 18, 1458-1461; e) K.-i. Takao, S. Noguchi, S. Sakamoto, M. Kimura, K. Yoshida, K.-i. Tadano, J. Am. Chem. Soc 2015, 137, 15971-15977; f) M. Morkunas, M. E. Maier, Tetrahedron 2015, 71, 9662-9666; g) L. Song, H. Yao, R. Tong, Org. Lett. 2014, 16 3740-3743; h) T. H. Jepsen, S. B. Thomas, Y. Lin, C. I. Sathais, I. de Miguel, S. A. Snyder, Angew. Chem. Int. Ed. 2014, 53, 6747-6751 Angew. Chem. 2014, 126, 6865-6869; i) D. N. Tran, N. Cramer, Chem. Eur. J. 2014, 20, 10654-10660; j) J. T. J. Spence, J. H. George, Org Lett. 2013, 15, 3891-3893; k) R. E. Ziegler, S.-J. Tan, T.-S. Kam, J. A Porco Jr., Angew. Chem. Int. Ed. 2012, 51, 9348-9351; Angew. Chem. 2012, 124, 9482-9485; I) D. H. Liao, H. H. Li, X. G. Lei, Org. Lett. 2012 14, 18-21; m) J. C. Green, E. R. Brown, T. R. R. Pettus, Org. Lett. 2012, 14, 2929-2931; n) J. C. Green, S. Jiminez-Alonso, E. R. Brown, T. R. R. Pettus, Org. Lett. 2011, 13, 5500-5503.

[3] Selected examples: a) Y. F. Wong, Z. Wang, W.-X. Hong, J. Sun, Tetrahedron 2016, 72, 2748-2751; b) N. J. Willis, C. D. Bray, RSC Adv. 2015, 5, 80212-80215; c) Q. Li, T. Dong, X. Liu, X. Lei, J. Am. Chem. Soc. 2013, 135, 4996-4999; d) W. Wang, Z. Zheng, X. Wang, J. Chen, Eur. J. Org. Chem. 2013, 8299-8306; e) S. J. Gharpure, A. M. Sathiyanarayanan, P. K. Vuram, RSC Adv. 2013, 3, 18279-18282.

[4] P. Batsomboon, W. Phakhodee, S. Ruchirawat, P. Ploypradith, J. Org. Chem. 2009, 74, 4009-4012.

[5] L. M. Bishop, M. Winkler, K. N. Kouk, R. G. Bergma, D. Trauner, Chem. Eur. J. 2008, 14, 5405-5408.

[6] H. Sugimoto, S. Nakamura, T. Ohwada, J. Org. Chem. 2007, 72, 10088-10096.

[7] A. E. Mattson, K. A. Scheidt, J. Am. Chem. Soc. 2007, 129, 4508-4509.

[8] Y. Chen, M. G. Steinmety, J. Org. Chem. 2006, 71, 6053-6060.

[9] o-QMs generation by transition metal catalysis: a) R. jana, T. P. Pathak, K. H. Jensen, M. S. Sigman, Org. Lett. 2012, 14, 4074-4077; b) T. P. Pathak, M. S. Sigman, Org. Lett. 2011, 13, 2774-2777; c) T. P. Pathak, K. M. Gligorich, B. E. Welm, M. S. Sigman, J. Am. Chem. Soc. 2010 132, 7870-7871; d) K. H. Jensen, J. D. Webb, M. S. Sigman, J. Am. Chem. Soc. 2010, 132, 17471-17482; e) K. H. Jensen, T. P. Pathak, Y. Zhang, M. S. Sigman, J. Am. Chem. Soc. 2009, 131, 17074-17075; f) Y. Zhang, M. S. Sigman, J. Am. Chem. Soc. 2007, 129, 3076-3077.

[10] Selected recent examples of catalytic asymmetric reactions of o-QMs: a) S. K. Alamsetti, M. Spanka, C. Schneider, Angew. Chem. Int. Ed. 2016, 55, 2392-2396; Angew. Chem. 2016, 128, 2438-2442; b) F.-S He, J.-H. Jin, Z.-T. Yang, X. Yu, J. S. Fossey, W.-P. Deng, ACS Catal. 2016, 6, 652-656; c) Q. Wu, C. Ma, X.-H. Du, Y. Chen, T.-Z. Huang, X.-Q. Shi, S.-J. Tu, P.-J. Cai, Tetrahedron: Asymmetry 2016, 27, 306316; d) L. Garuana, M. Mondatori, V. Corti, S. Morales, A. Mazzanti, M. Fochi, L. Bernardi, Chem. Eur. J. 2015, 21, 6037-6041; e) Y. Huang, T. Hayashi, J. Am. Chem. Soc. 2015, 137, 7556-7559; f) S. Saha, C. Schneider, Chem. Eur. J. 2015, 21, 2348-2352; g) M. N. Grayson, J. M. Goodman, J. Org. Chem. 2015, 80, 2056-2061; h) L. Garuana, M. Mondatori, V. Corti, S. Morales, A. Mazzanti, M. Fochi, L. Bernardi, Chem. Eur. J. 2015, 21, 6037-6041; i) S. Saha, S. K. Alamsetti, C. Schneider, Chem. Commun. 2015, 51, 1461-1464; j) S. Saha, C Schneider, Org. Lett. 2015, 17, 648-651; k) W. Zhao, Z. Wang, B. Chu, J. Sun, Angew. Chem. Int. Ed. 2015, 54, 1910-1913; Angew. Chem. 2015, 127, 1930-1933; I) W. Guo, B. Wu, X. Zhou, P. Chen, X. Wang, Y. G. Zhou, Y. Liu, C. Li, Angew. Chem. Int. Ed. 2015, 54, 4522-4526 Angew. Chem. 2015, 127, 4605-4609; m) Z. Wang, F. Ai, Z. Wang, W. Zhao, G. Zhu, Z. Lin, J. Sun, J. Am. Chem. Soc. 2015, 137, 383-389; n) G. C. Tsui, L. Liu, B. List, Angew. Chem. Int. Ed. 2015, 54, 77037706; Angew. Chem. 2015, 127, 7814-7818; o) J.-J. Zhao, Y.-C. Zhang M.-M. Xu, M. Tang, F. Shi, J. Org. Chem. 2015, 80, 10016-10024; p) O. El-Sepelgy, S. Haseloff, S. K. Alamsetti, C. Schneider, Angew. Chem. Int. Ed. 2014, 53, 7923-7927; Angw. Chem. 2014, 126, 8057-8061; q) R.-Y. Zhu, C.-S. Wang, J. Zhang, F. Shi, S.-J. Tu, J. Org. Chem. 2014,
79, 9305-9312; r) C.-C. Hsiao, H.-H. Liao, M. Rueping, Angew. Chem. Int. Ed. 2015, 54, 13258-13263; Angew. Chem. 2014, 126, 13474 13479 ; s) Y. Luan, S. E. Schaus, J. Am. Chem. Soc. 2012, 134, 1996519968.

[11] Selected examples of catalytic asymmetric intermolecular $[4+2]$ cycloadditions of $o-Q M s:$ a) Q. Wu, J. Zhao, S. Sun, M. Tu, F. Shi, Acta Chim. Sinica. 2016, 74, 576-581; b) Y.C. Zhang, Q.-N. Zhu, X. Yang, L.-J. Zhou, F. Shi, J. Org. Chem. 2016, 81, 1681-1688; c) C. -C. Hsiao, S. Raja, H. H. Liao, I. Atodireisei, M. Rueping, Angew. Chem. Int. Ed. 2015, 54, 5762-5765; Angew. Chem. 2015, 127, 5854-5857; d) J. J. Zhao, S. B. Sun, S. H. He, Q. Wu, F. Shi, Angew. Chem. Int. Ed. 2015, 54, 5460-5464; Angew. Chem. 2015, 127, 5550-5554; e) E. AldenDanforth, M. T. Scerba, T. Lectka, Org. Lett. 2008, 10, 4951-4953; f) M. A. Marsini, Y. Huang, C. C. Lindsey, K.-L. Wu, T. R. R. Pettus, Org. Lett. 2008, 10, 1477-1480; g) C. Selenski, T. R. R. Pettus, J. Org. Chem. 2004, 69, 9196-9203.

[12] Selected examples of confined Brønsted acid catalysis: a) L. Liu, M. Leutzsch, Y. Zheng, M. W. Alaschraf, W. Thiel, B. List, J. Am. Chem Soc. 2015, 137, 13268-13271; b) J. H. Kim, I. Čorić, S. Vellalath, B. List, Angew. Chem. Int. Ed. 2013, 52, 4474-4477; Angew. Chem. 2013, 125, 4570-4573; c) I. Čorić, B. List, Nature 2012, 483, 315-319; d) S Vellalath, I. Čorić B. List, Angew. Chem. Int. Ed. 2010, 49, 9749-9752; Angew. Chem. 2010, 122, 9943-9946; e) S. Liao, I. Čorić, Q. Wang, B. List, J. Am. Chem. Soc. 2012, 134, 10765-10768; f) Y.-Y. Chen, Y.-J. Jiang, Y.-S. Fan, D. Sha, Q. Wang, G. Zhang, L. Zheng, S.-Q. Zhang, Tetrahedron: Asymmetry 2012, 134, 904-909; g) S. Kan, Y. Jin, X. He, J. Chen, H. Wu, P. Ouyang, K. Guo, Z. Li, Polym. Chem. 2013, 4, 5432-5439; h) G. Jindal, R. B. Sunoj, Angew. Chem. Int. Ed. 2014, 53, 4432-4436; Angew. Chem. 2014, 126, 4521-4525.

[13] a) H. Miyazaki, Y. Honda, K. Honda, S. Inoue, Tetrahedron Lett. 2000, 41, 2643-2647; b) H. Miyazaki, K. Honda, M. Asami, S. Inoue, J. Org Chem. 1999, 64, 9507-9511; c) S. Inoue, M. Asami, K. Honda, H Miyazaki, Chem. Lett. 1996, 889-890; d) Z. G. Lu, S. Inoue Heterocycles 1992, 34, 1107-1117; e) T. Inoue, S. Inoue, K. Sato, Chem. Lett. 1990, 55-58, f) T. Inoue, S. Inoue, K. Sato, Bull. Chem. Soc. Jpn. 1990, 63, 1062-1068; g) T. Inoue, S. Inoue, K. Sato. Bull. Chem. Soc. Jpn. 1990, 63, 1647-1652; h) T. Inoue, S. Inoue, K. Sato Chem. Lett. 1989, 653-656.

[14] a) J. S. Yadav, B. V. S. Reddy, K. Sadashiv, B. Padmavani, Adv. Synth Catal. 2004, 346, 607-610; b) J. S. Yadav, B. V. S. Reddy, C. V. Rao, K. V. Rao, J. Chem. Soc., Perkin Trans. 1, 2002, 1401-1404, c) J. S Yadav, B. V. S. Reddy, M. Aruna, M. Thomas, Synthesis 2002, 2, $217-$ 220.

[15] a) L.-M. Zhao, A.-L. Zhang, H.-S. Gao, J.-H. Zhang, J. Org. Chem. 2015, 80, 10353-10358; b) B. Sarmah, G. Baishya, N. Hazarika, P. J. Das, Synlett 2014, 25, 2151-2155.

[16] a) A. C. Spivey, L. Laraia, A. R. Bayly, H. S. Rzepa, A. J. P. White, Org Lett. 2010, 12, 900-903; b) B. V. S. Reddy, S. R. Anjum, G. M. Reddy, T. P. Rao, Synlett. 2011, 20, 2951-2954; c) C. S. Sundar, M. R. Reddy, B. Sridhar, S. K. Kumar, C. S. Reddy, B. V. S. Reddy, Synlett. 2011, 20, 2951-2954; d) C. S. Sundar, M. R. Reddy, B. Sridhar, S. K. Kumar, C. S. Reddy, B. V. S. Reddy, Tetrahedron Lett . 2014, 55, 4236-4239.

[17] For selected reviews on asymmetric Brønsted acid catalysis: a) H. Wu, Y.-P. He, F. Shi, Synthesis. 2015, 47, 1990-2016; b) M. Rueping, A Kuenkel, I. Atodiresei, Chem. Soc. Rev. 2011, 40, 4539-4549; c) M. Terada, Synthesis 2010, 12, 1929-1982; d) G, Adair, S. Mukherjee, B. List, Aldrichimica Acta. 2008, 41, 31-41; e) T. Akiyama, Chem. Rev. 2007, 107, 5744-5758.

[18] M. van Gemmeren, F. Lay, B. List, Aldrichimica Acta 2014, 47, 3-13.

[19] Please see the Supporting Information. CCDC 1519892 (3h) contains the supplementary crystallographic data for this paper. These data can be obtained free of charge from The Cambridge Crystallographic Data Centre via www.ccdc.cam.ac.uk/data request/cif.

[20] Y. Xie, G.-J. Cheng, S. Lee, P. S. J. Kaib, W. Thiel, B. List, J. Am. Chem. Soc. 2016, 138, 14538-14541. 